\title{
OBITUARY
}

\section{DR. J. WALLACE GRAHAM}

Dr. Wallace Graham, M.D.(Toronto), F.R.C.P., F.R.C.P.(C.), died in Toronto on December 17, 1962, at the age of 56 . He was born in Sudbury, Ontario, the son of a clergyman.

Wallace Graham was a man of many talents. When studying first dentistry and later medicine at the University of Toronto, he made his name as an athlete. In 1926 he established a track record for the three miles which stood for 25 years, and he was also an outstanding ice-hockey player. After qualifying, he spent a period of postgraduate study in London and obtained the M.R.C.P. He was elected F.R.C.P. in 1956.

During the second world war he served in the Royal Canadian Navy as a surgeon lieutenantcommander and spent arduous years on convoy duty in the North Atlantic. After the war he decided to specialize in rheumatology; he played a large part in the formation and fund-raising programme of the Canadian Arthritis and Rheumatism Society, and was elected its first President in 1948. Through his personal achievements he became one of Canada's outstanding medical men, and by his enthusiasm and example stimulated increasing interest throughout his country in the study of the rheumatic diseases. He was appointed Chief of the Arthritis Service at the Sunnybrook Veterans' Hospital, Toronto, and started there an active research programme, attracting able young doctors to his department. He took a prominent part in the development of rheumatology both in Canada and throughout North America, and served successively as President of the Canadian Rheumatism Association, and the Pan-American League Against Rheumatism, and Vice-President of the
Ligue Internationale contre le Rhumatisme. He was appointed Chairman of the Medical Advisory Board of the Canadian Arthritis and Rheumatism Society from 1949 to 1959 and Chairman of the Gairdner Foundation from 1960 to 1962 . As reported in the Annals in 1961, besides his large consulting practice, Wallace Graham became head of one of the three medical services at the Toronto General Hospital. In addition, a new rheumatic diseases unit was formed within the department of medicine in the University of Toronto under his directorship, and this included a 30-bed long-stay active treatment division at the Queen Elizabeth Hospital as well as the Departments at Sunnybrook and the Toronto General. Last year he undertook the high office of President of the Toronto Academy of Medicine.

"Wally" Graham was beloved by a host of people at home and abroad. He travelled widely and wherever he went attracted friends by his dynamic energy and generous personality. Many doctors and their wives will remember the gracious hospitality of Wallace Graham and his charming family at the Meeting of the International League in Toronto in 1957 where he was the chief organizer. He had a large circle of friends outside medicine, particularly in the arts. At the age of 50 he learnt to play the piano and found immense pleasure in it.

His visits to Great Britain were always a stimulus to physicians interested in the rheumatic diseases. His death at the height of his career is a sad loss to rheumatology throughout the world and we extend our deepest sympathy to his wife and daughter, and to the son who is following him in the profession. 